16. Mouse cerebellar cultures were prepared and maintained by the method of K. Schilling, M. Dickinson, J. Connor, and J. Morgan (Neuron, in press) as previously described (6). Cultures used for recording had been maintained in vitro for 12 to 24 days. PNs were chosen for recording by distinct morphological criteria (large round soma, prominent dendritic arbor) as verified by staining with the PNspecific immunochemical markers PEP-19 [L Sangameswaran, J. Hempstead, J. Morgan, Proc. Nati. Acad. Sci. U.S.A. 86, 5651 (1989)] and calbindin-D ${ }_{28 k}$ [M. Thomasset et al., Dev. Pharmacol. Ther. 7, 6 (1984)]. Nystatin patch electrodes [R. Horn and A. Marty, J. Gen. Physiol. 92, 145 (1988)] were attached to PN somata and were used to apply a holding potential of $-80 \mathrm{mV}$. Iontophoresis electrodes (tip diameter, $<0.5 \mu \mathrm{m}$ ) were filled with excitatory amino acid receptor agonists and were positioned $-20 \mu \mathrm{m}$ away from a largecaliber dendrite 10 to $20 \mu \mathrm{m}$ from the soma. Pulses of agonists ( 30 to $100 \mathrm{~ms}$ duration) were applied at a frequency of $0.05 \mathrm{~Hz}$. After acquisition of $15 \mathrm{~min}$ of baseline responses, we induced LTD by pairing six successive glutamate test pulses with six 4-s depolarization steps to $-10 \mathrm{mV}$, timed so that the depolarization onset preceded the glutamate pulse by $500 \mathrm{~ms}$. This treatment reliably induced a stable depression of the glutamate-mediated inward current (typically 50 to $65 \%$ of its baseline value) that was independent of alterations in input resistance or resting potential (6; D. J. Linden and J. A. Connor, in preparation). Cells were bathed in a solution (adjusted to $\mathrm{pH} 7.35$ with $\mathrm{NaOH}$ ) that contained $\mathrm{NaCl}(150$ $\mathrm{mM}), \mathrm{KCl}(5 \mathrm{mM}), \mathrm{CaCl}_{2}(2 \mathrm{mM}), \mathrm{MgCl}_{2}(0.8 \mathrm{mM})$ Hepes $(10 \mathrm{mM})$, glucose $(10 \mathrm{mM})$, tetrodotoxin $(0.005 \mathrm{mM})$, and picrotoxin $(0.1 \mathrm{mM})$. Tetrodotoxin and picrotoxin were added to the external saline to improve the resolution of the voltage clamp and to block spontaneous synaptic potentials, but the addition of these compounds was not required for the induction of LTD. For recordings of voltage-gated $\mathrm{Ca}^{2+}$ currents (as in Fig. 1C), $10 \mathrm{mM}$ TEA-C was added. The internal saline (adjusted to $\mathrm{pH} 7.35$ with $\mathrm{KOH}$ ) consisted of $\mathrm{K}_{2} \mathrm{SO}_{4}(95 \mathrm{mM}), \mathrm{KCl}(15 \mathrm{mM}), \mathrm{MgCl}_{2}(8$ $\mathrm{mM})$, and Hepes (10 mM). For $\mathrm{Ca}^{2+}$ current record ing, $\mathrm{C}_{2} \mathrm{SO}_{4}$ and $\mathrm{CsCl}$ were substituted for $\mathrm{K}_{2} \mathrm{SO}_{4}$ and $\mathrm{KCl}$, respectively, in an equimolar fashion. Patch electrodes were pulled from N51A glass (Garner Glass Co. Claremont, CA) and polished on a microforge to yield a resistance of 1 to 3 megohms when measured with nomal internal and external salines. Nystatin (250 $\mu \mathrm{g} / \mathrm{ml}$ ) was added to the electrode filling saline. This concentration gave access resistance to the cell that was typically $<10$ megohms. Only cells with stable resting potentials of $>-45 \mathrm{mV}$ were used. Membrane currents induced by application of excitatory amino acids were stored on a chart reconder that imposed a 0 - to 30-Hz bandpass. Membrane currents in response to voltage steps were filtered at $3 \mathrm{kHz}$, digitized with a 12-bit analog-to-digital converter operating at a sampling frequency of $20 \mathrm{kHz}$, and stored on the hard disk of an INDEC-LSI-11/23 computer. Leakage current was determined from $10-\mathrm{mV}$ hyperpolarizing pulses and was digitally subtracted from records of voltage gated currents. Experiments were conducted at $22^{\circ}$ to $24^{\circ} \mathrm{C}$. Imaging of intracellular free $\mathrm{Ca}^{2+}$ with the indicator fura-2/AM was performed as described [J. A Connor, Proc. Natl. Acad. Sci. U.S.A. 83, 6179 (1986)].

17. Excitory amino acid receptor agonists were delivered by iontophoresis and were prepared in $10 \mathrm{mM}$ Hepes as follows: $10 \mathrm{mM}$ glutamate ( $\mathrm{pH} 7.1$ ); 10 $\mathrm{mM}$ quisqualate (pH 7.2); $10 \mathrm{mM}$ AMPA (pH 7.1); $100 \mathrm{mM}$ NMDA (pH 7.3). These compound were delivered through polished patch pipettes (re sistance, 4 to 6 megohms when filled with norma internal saline) with negative current pulses. Braking currents were applied to prevent drug leakage.

18. E. Kobayashi, H. Nakano, M. Morimoto, $T$ Tamaoki, Biochem. Biophys. Res. Commun. 159, 548 (1989). The following $\mathrm{IC}_{50}$ values are reported for calphostin $\mathrm{C}$ inhibition of purified protein kinases, with a histone protein substrate: PKC, $0.05 \mu \mathrm{M}$ adenosine $3^{\prime}, 5^{\prime}$-monophosphate (cAMP)-dependent kinase, $>50.00 \mu \mathrm{M}$; guanosine $3^{\prime}, 5^{\prime}$-mono phosphate (cGMP)-dependent kinase, $>25.00 \mu \mathrm{M}$; myosin light-chain kinase $>5.00 \mu \mathrm{M}$.
19. P. D. Davis et al., FEBS Lett. 259,61 (1989). RO-318220 is referred to as compound 3 in this reference. The following inhibition concentration $\left(\mathrm{IC}_{50}\right)$ values are reported for RO-31-8220 inhibirion of purified protein kinases as measured in the presence of ATP $(10 \mu \mathrm{M})$ with a histone protein substrate: PKC, $0.01 \mu \mathrm{M}$; cAMP-dependent kinase, I.5 $\mu \mathrm{M} ; \mathrm{Ca}^{2+} /$ calmodulin dependent kinase, $17 \mu \mathrm{M}$.

20. C. House and B. E. Kemp, Science 238, 1726 (1987); R. Malinow, H. Schulman, R. W. Tsien, ibid. 245, 862 (1989)

21. O. P. Hamill, A. Marty, E. Neher, B. Sakmann, F. J Sigworth, Pfweger's Arch. 391, 85 (1981). Conventional whole-cell recordings (Fig. 1C) were made with the same configuration as described for perforated patch recording, except that a different internal saline was used and nystatin was omitted from the recording electrode. This internal saline contained $\mathrm{KCl}(140$ $\mathrm{mM}$ ), Hepes ( $10 \mathrm{mM}$ ), and Mg-ATP ( $2 \mathrm{mM}$ ), adjusted to $\mathrm{pH} 7.35$ with $\mathrm{KOH}$. Chelators of $\mathrm{Ca}^{2+}$ were omitted to avoid blocking induction of LTD. When $\mathrm{K}_{4}$ BAPTA $(20 \mathrm{mM})$ was added to block LTD, $50 \mathrm{KCl}$ was removed to compensate for the change in osmolarity.

22. D. J. Linden and J. A. Connor, unpublished observations.

23. Studies with exogenous agonists have shown a developmental decrease in the response of PNs to NMDA, resulting in a complete lack of sensitivity to this compound in the adult [J. L. Dupont, G. Gardette,

F. Crepel, Dev. Brain Res. 34, 59 (1987); G. Garthwaite, B. Yamani, J. Garthwaite, ibid. 36, 288 (1987); E. Audinat, T. Knopfel, B. H. Gahwikr, J. Physiol. (London) 430, 297 (1990)]. Our cultures of embryonic PNs showed NMDA responses typical of those seen in other neuronal types: that is, they were attenuated by DL-2-amino-5-phosphonopentanoic acid (AP5) and exhibited a $\mathrm{Mg}^{2+}$ and voltage-dependent block. When the membrane potential was clamped to $-80 \mathrm{mV}$, the NMDA response became very small $(<10 \%$ of the glutamate current was blocked by $20 \mu \mathrm{M}$ AP5 at this potential). To produce NMDA currents of easily measurable amplinude (as in Fig. 3), membrane potential was clamped to $-65 \mathrm{mV}$, and NMDA pulses were typically applied for durations two to three times that of AMPA.

24. M. Castagna et al., J. Biol. Chem. 257, 7847 (1982).

25. Y. Nishizuka, Science 233, 305 (1986).

26. R. Malinow, D. V. Madison, R. W. Tsien, Nature 335, 820 (1988); T. H. Brown, P. F. Chapman, E. W. Kairiss, C. L. Keenan, Science 242, 724 (1988).

27. We thank K. Schilling, who developed the cell culture technique used in this study; M. Smeyne and R. Sun for technical assistance; W. Muller, $M$. Dickinson, and J. Petrozzino for helpful discussion; and G. Lawton (Roche Welwyn, United Kingdom) for providing RO-31-8220.

8 July 1991; accepted 10 September 1991

\title{
Targeting of the Master Receptor MOM19 to Mitochondria
}

\section{Helmut Schneider, Thomas Söllner, Klaus Dietmeier, Christoph ECKERSKORN, FrITz LotTSPEICH, Barbara TRÜlzSCH, Walter Neupert, Nikolaus PfanNeR*}

The targeting of proteins to mitochondria involves the recognition of the precursor proteins by receptors on the mitochondrial surface followed by insertion of the precursors into the outer membrane at the general insertion site GIP. Most mitochondrial proteins analyzed so far use a mitochondrial outer membrane protein of 19 kilodaltons (MOM19) as an import receptor. The gene encoding MOM19 has now been isolated. The deduced amino acid sequence predicts that MOM19 is anchored in the outer membrane by an $\mathrm{NH}_{2}$-terminal hydrophobic sequence, while the rest of the protein forms a hydrophilic domain exposed to the cytosol. MOM19 was targeted to the mitochondria via a pathway that is independent of protease-accessible surface receptors and controlled by direct assembly of the MOM19 precursor with GIP.

\section{$\mathrm{T}$} HE BIOGENESIS OF MITOCHONDRIA involves the translocation of cytosolically synthesized precursor proteins into or across the organellar membranes (1, 2). In Neurospora crassa, two mitochondrial outer membrane proteins (MOMs) were identified as import receptors for precursor proteins. The 19-kD protein MOM19 functions as a receptor for most precursors analyzed, including all precursors that carry an $\mathrm{NH}_{2}$-terminal signal sequence $(3-5)$, and is referred to as the master receptor. The 72 -

H. Schneider, T. Söllner, K. Dietmeier, B. Trülzsch, W. Neupert, N. Pfanner, Institut für Physiologische Chemie, Universität München, Goethestraße 33, W-8000 München 2, Germany.

C. Eckerskorn, F. Lottspeich, Max-Planck-Institut für Biochemie, W-8033 Martinsried, Germany.

*To whom correspondence should be addressed.
$\mathrm{kD}$ protein MOM72 is a receptor for the precursor of the adenosine diphosphateadenosine triphosphate (ADP-ATP) carrier, which contains internal targeting signals (4, 6). Precursor proteins interact with these receptors and are inserted into the outer membrane at a common site, termed the general insertion site (general insertion protein $=\operatorname{GIP})(7,8)$. The $38-\mathrm{kD}$ protein MOM38 forms part of the GIP and is assembled with MOM19 and MOM72 in the mitochondrial receptor complex (9). To determine the mechanism by which the master receptor is targeted to mitochondria, we investigated the biogenesis of MOM19.

A full-length cDNA clone that encodes MOM19 from $N$. crassa was isolated (10) and used to obtain the complete MOMI9 gene (11). The nucleotide sequences of both 
the cDNA and the gene (containing three introns) were determined. The predicted protein, with 181 amino acids (Fig. 1A) and a molecular mass of 20,206 , was in good of $19 \mathrm{kD} \mathrm{(3).} \mathrm{The} 3^{\prime}$-untranslated region of the cDNA was 642 nucleotides (nt) and contained a fragmentary poly(A) stretch. To confirm the identity of the MOM19 cDNA, we purified MOM19 from isolated mitochondria (3) and determined amino acid sequences of four peptides derived. All of the peptide sequences matched the deduced amino acid sequence, with the exception of the $\mathrm{NH}_{2}$-terminal methionine, which was not found in the mature protein (Fig. 1 caption).

MOM19 contains a hydrophobic sequence of 26 amino acids at the $\mathrm{NH}_{2}$ terminus (Fig. 1A) that may anchor the protein in the outer membrane. The rest of the protein is hydrophilic and probably forms a cytosolic domain, in agreement with the protease accessibility of MOM19 in intact mitochondria (3). In addition, MOM19 contains clusters of arginine residues (Fig. 1A), and amino acid residues 42 to 59 are predicted to form an amphipathic $\alpha$ helix (12). Amino acid residues 92 to 174 of agreement with the apparent molecular size

MOM19 are $42 \%$ similar to residues 712 to 797 of $\alpha$-actinin from Dictyostelium discoideum (13), suggesting that MOM19 could function in the interaction of mitochondria with the cytoskeleton. Residues 107 to 160 show a similarity of $45 \%$ to residues 419 to 469 of the plasma membrane $\mathrm{H}^{+}$-dependent ATPase $\left(\mathrm{H}^{+}\right.$-ATPase) of Schizosaccharomyces pombe (14).

The MOM19 cDNA was expressed in Escherichia coli, and inclusion bodies containing MOM 19 were purified, separated on SDS-polyacrylamide gels, and transferred to nitrocellulose. The protein band corresponding to MOM19 was used to generate polyclonal antibodies in rabbits. These antibodies specifically recognized MOM19 in isolated mitochondria by immunodecoration and immunoprecipitation as shown for antibodies prepared against purified MOM19 (3). To determine whether antibodies prepared against cloned MOM19 showed the same specific inhibitory effect on mitochondrial protein import as antibodies prepared against MOM19 purified from outer membranes (3), immunoglobulins G (IgGs) and Fab fragments were prepared. Fab fragments were prebound to isolated $N$. crassa mitochondria, and the in vitro import

A

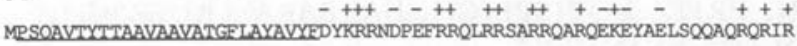
QMVDEAKEEGFPTTSDEKEAYFLEQVQAGEILGQDPTKAIDASLAFYKALKVYPTPGDLISTYDKTVA KPIIDILAEMIAYDPSLKIGTNYTGGVDVAEIMREMASAPGVGID

Fig. 1. Primary structure of N. crassa MOM19. (A) Amino acid sequence of MOM19. A full-length cDNA coding for $N$. crassa MOM19 was isolated from a cDNA library in $\lambda g t 11$ (10) by antibody screening (23), and the cDNA was used to obtain the gene from a genomic library in pBR322 (11). The nucleotide sequence data are available from GenBank under accession number M80528. Abbreviations for the amino acid residues are the following: A, Ala; C, Cys; D, Asp; E, Glu; F, Phe; G, Gly; H, His; I, Ile; K, Lys; L, Leu; M, Met; N, Asn; P, Pro; Q, Gln; R, Arg; S, Ser; T, Thr; V, Val; W, Trp; and Y, Tyr. The hydrophobic segment of MOMI9 is underlined. Sequence analysis of the $\mathrm{NH}_{2}$ terminus and of three tryptic fragments of purified MOM19 (3) was performed as described $(24,25)$. The sequences were identical to the residues 2 through 27,54 through 58,107 through 116 , and 171 through 179 of the deduced sequence. (B) Antibodies prepared against the cloned MOM19 inhibit the import of precursor proteins into mitochondria. The CDNA of MOM19 cloned into PUHE25 was expressed in the E. coli strain BMH71-18. Inclusion bodies containing MOM19 were isolated, and antibodies (IgGs and Fab fragments) were prepared $(3,26)$. Fab fragments [15 $\mu \mathrm{g}$, except lanes 1 and 7 (no Fab fragments) and lane $2(5 \mu \mathrm{g})]$ were prebound to isolated $N$. crassa mitochondria (10 $\mu \mathrm{g}$ of protein). Rabbit reticulocyte lysate $(5 \mu \mathrm{l})$ containing the ${ }^{35} \mathrm{~S}$-labeled precursor proteins of $F_{1}-A T P a s e$ subunit $\beta\left(F_{1} \beta\right)$, cytochrome $c_{1}$ (Cyt. $\left.c_{1}\right)$, porin, or ADP-ATP carrier (AAC), respectively, was added to the energized mitochondria $(3,6,26)$. After incubation for $7 \mathrm{~min}$ at

$25^{\circ} \mathrm{C}$, the mitochondria were treated with proteinase $\mathrm{K}(26)$, and reisolated, and the proteins were analyzed by SDS-polyacrylamide gel electrophoresis (SDS-PAGE), fluorography, and laser densitometry. The amount of protein imported into mitochondria not carrying Fab fragments (lane 1, control) was set to $100 \%$. The values are averages of five determinations with SEMs less than $5 \%$. Lanes 2 and 3, anti-MOM19c, Fab fragments to MOM19 expressed in E. coli; lane 4, anti-MOM19, Fab fragments to MOM19 obtained from purified MOMs (3); lane 5, anti-Porin, Fab fragments to porin; lane 6, preimmune Fab fragments; "bypass" (lane 7) denotes import into mitochondria pretreated with trypsin $(20 \mu \mathrm{g} / \mathrm{ml})(3,6,21,26) ; \mathrm{mF}_{1} \beta$ denotes mature $\mathrm{F}_{1} \beta$. of various precursor proteins was analyzed (Fig. 1B). The import of $F_{1}$-ATPase subunit $\beta$, cytochrome $c_{1}$, and porin was strongly inhibited, whereas the import of the ADPATP carrier [which uses both receptors, but predominantly MOM72 $(4,6)]$ was only partly inhibited. Thus, the inhibitory effect of the antibodies to MOM19 is independent of the source of the MOM19 used for immunization, indicating that the inhibitory effect of the original antibodies to MOM19 was not caused by another MOM protein that might have been present in the preparation used for generation of the original antibodies (3).

The precursor of MOM72 uses MOM19 as a receptor (6). Thus, we sought to determine whether the master receptor MOM19 needed a receptor for import. The MOM19 precursor was synthesized in rabbit reticulo- $\infty$ cyte lysate in the presence of $\left[{ }^{35} S\right]$ methionine, and lysate containing MOMl9 precursor was incubated with isolated $N$. crassa mitochondria. The precursor efficiently associated with the mitochondria (about $80 \%$ of the precursor added), whereas no association was found with other membranes such $Z$ as microsomes (Fig. 2A). To analyze for $ᄃ$ correct import of MOM19 into mitochondria in vitro, we made use of a property of MOM19 imported in vivo. A treatment of mitochondria with elastase produces a characteristic proteolytic pattern of MOM19; in particular, a $17-\mathrm{kD}$ fragment (termed MOM19') is formed (3). The identical pattern was generated from MOM19 imported in vitro (Fig. 2B). The nonimported precursor in the reticulocyte lysate did not yield this pattern but was further degraded (Fig. 2B). Using the formation of MOM19' as a specific assay for the import of MOM19, we found that a pretreatment of mitochondria with protease did not inhibit the import of MOM19 (Fig. 2C). We performed the assay for import of MOM19 in the kinetically linear range; pretreatment with protease completely degraded the preexisting surface receptors MOM19 and MOM72 and inhibited the binding and import of numerous other precursor proteins $(3,4,6,8)$. Thus, the import of MOM19 does not require any of the known receptors or other proteaseaccessible surface receptors.

The finding of a means of import of MOM19 independent of a surface receptor raises the question of how a mitochondrion controls the specificity of import of its master receptor. In the mitochondrial receptor complex, MOM19 is particularly tightly associated with MOM38 (9). The specific interaction with MOM38 might thus be responsible for the specificity of MOM19 import. The MOM38 from $N$. crassa is a tightly folded protein, and antibodies recog- 
Flg. 2. Lack of a requirement of a surface receptor for the import of MOM19 into $N$. crassa mitochondria. (A) The precursor of MOM19 efficiently binds to isolated mitochondria but not to microsomes. MOM19 (cDNA cloned into pGEM4) was synthesized in rabbit reticulocyte lysate in the presence of $\left[{ }^{35}\right.$ S]methionine $(26)$. Lysate $(2 \mu \mathrm{l})$ was incubated with isolated mitochondria ( $10 \mu \mathrm{g}$ of protein) or microsomes (10 $\mu \mathrm{g}$ of protein) for $15 \mathrm{~min}$ at $25^{\circ} \mathrm{C}$ in a final volume of $75 \mu \mathrm{l}$ (including $100 \mathrm{mM}$ of $\mathrm{KCl}$ ) as described (26). The membranes were reisolated by centrifugation and washed in $100 \mathrm{mM}$ sucrose, $1 \mathrm{mM}$ EDTA, $10 \mathrm{mM}$ MOPS, $\mathrm{pH} 7.2,100 \mathrm{mM} \mathrm{KCl}$, and the proteins were analyzed as described in the caption of Fig. 1B. The values are averages of four determinations with SEMs less than 7\%. The precursor of MOM19 showed the same apparent size as the mature protein, and its import into mitochondria did not require a membrane potential across the inner membrane, as is generally found with outer membrane proteins (2). F, free; MB, membrane bound. (B) Formation of a characteristic 17-kD fragment (MOM19') of imported MOM19. MOM19 synthesized in vitro was imported into isolated mitochondria for $7 \mathrm{~min}$ at $25^{\circ} \mathrm{C}$. After treatment with elastase, the mitochondria were reisolated, washed, and analyzed by SDS-PAGE and fluorography. From parallel samples, mitochondria were transferred to nitrocellulose and treated with antibodies against MOM19 (3) (import in vivo). Rabbit reticulocyte lysate containing the precursor of MOM19 was treated with elastase under the conditions used for the treatment of mitochondria (3) (precursor). (C) Import of MOM19 into mitochondria does not require a surface receptor. Mitochondria were pretreated with trypsin (26) and incubated with reticulocyte lysate containing the precursors of $M O M 19(\bullet), F_{1} \beta$ $(\Delta)$, or AAC ( $\mathbf{G})$ for $5 \mathrm{~min}$ at $15^{\circ} \mathrm{C}$, followed by a treatment with elastase. The amount of protein imported into mitochondria not treated with trypsin was set to $100 \%$ (control). The values are averages of five
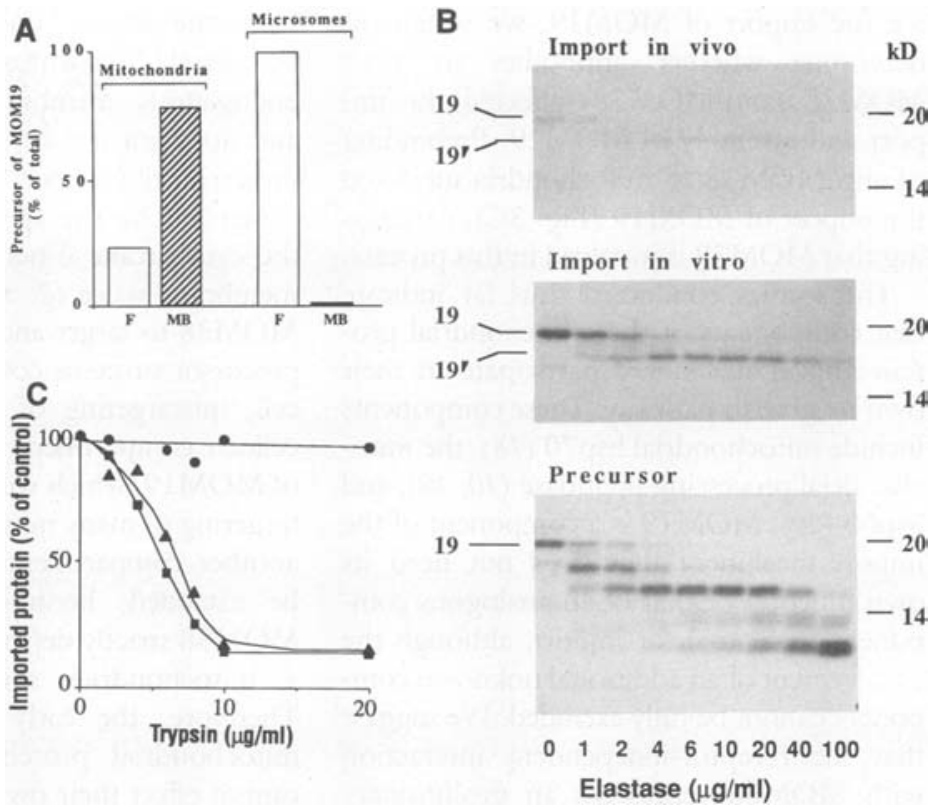

determinations with SEMs less than $5 \%$. The rate of import linearily depended on the time of incubation and the amount of mitochondria. Preincubation of the mitochondria with antibodies to MOM19 (3) also did not inhibit the import of newly synthesized MOMI9.
A

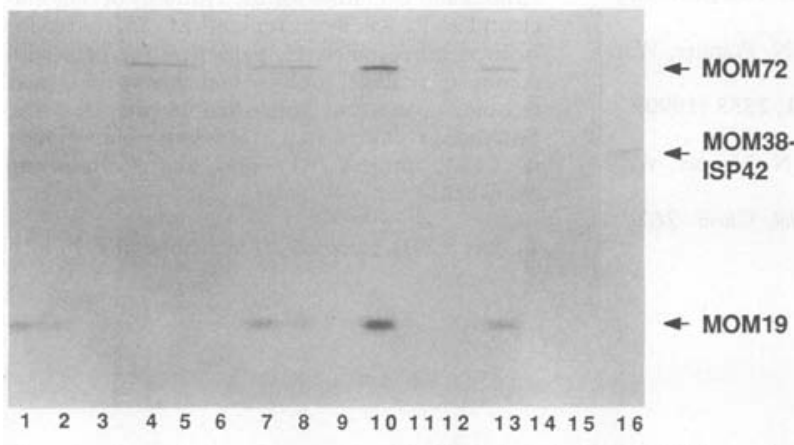

Fig. 3. Assembly of $N$. crassa MOM19 and MOM72 into the receptor complex of S. cerevisiae mitochondria. (A) Assembly into yeast mitochondria. Rabbit reticulocyte lysates $(7.5 \mu \mathrm{l})$ containing the ${ }^{35} \mathrm{~S}$-labeled precursors of $N$. crassa MOM19 (lanes 1 through 3 and 7 through 15) and MOM72 (lanes 4 through 15) were incubated with isolated yeast mitochondria $(25 \mu \mathrm{g}$ of protein) for $5 \mathrm{~min}$ at $25^{\circ} \mathrm{C}(26)$ (lanes 10 through 12 received mitochondria lysed with buffer containing $0.5 \%$ digitonin). The mitochondria of lanes 1 through 9 and 13 through 15 were reisolated, washed in $100 \mathrm{mM}$ sucrose, $1 \mathrm{mM}$ EDTA, $10 \mathrm{mM}$ MOPS, $\mathrm{pH} 7.2$, and solubilized in buffer containing $0.5 \%$ digitonin (lanes 1 through 9 ) (9) or in SDS-containing buffer (lanes 13 through 15) $(3,9)$. Immunoprecipitations were performed with antibodies directed to $N$. crassa MOM19 (lanes 1, 7, 10, and 13), MOM72 (lanes 4, 7, 10, and 13), yeast MOM38 (=ISP42) (lanes $2,5,8,11$, and 14), and preimmune antibodies (lanes $3,6,9,12$, and 15) (9). The specificity of the antibodies to yeast MOM38 was shown by immunoprecipitation of SDS-lysed yeast mitochondria labeled with ${ }^{35} \mathrm{~S}$ (lane 16). (B) Assembly of MOM19 does not require a known surface receptor.

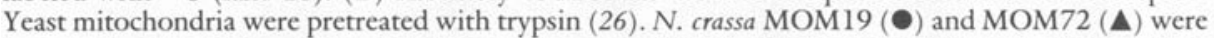
imported, and coimmunoprecipitations with anti-MOM38-ISP42 antibodies were performed as described above. The amount of protein that coprecipitated with mitochondria that were not treated with trypsin was set to $100 \%$ (control) (similar results were obtained when the import was performed at lower temperature, $15^{\circ} \mathrm{C}$ or $0^{\circ} \mathrm{C}$ ). The values are averages of five determinations with SEMs less than 6\%. (C) MOM38 (=ISP42) is needed for import of MOM19. Isolated yeast mitochondria $(10 \mu \mathrm{g})$ were preincubated with IgGs to MOM38 (closed symbols) or preimmune IgGs (open symbols) $(3,6,26)$. Precursors of MOM19 (-) and AAC (匹) were imported, and the mitochondria were treated with elastase as described above. For import of MOM19, the mitochondria were pretreated with trypsin $(5 \mu \mathrm{g} / \mathrm{ml})$. The amount of protein imported into mitochondria not carrying IgGs was set to $100 \%$ (control). The values are averages of at least three determinations with SEMs less than $8 \%$. nizing the native protein are not available (9), rendering a direct assay with $N$. crassa mitochondria impossible. The Saccharomyces cerevisiae equivalent of MOM38, also termed ISP42 $(15,16)$, is more easily accessible to antibodies, probably as a result of an extra sequence of about 20 amino acid residues at the $\mathrm{NH}_{2}$ terminus (9). We prepared monospecific antibodies to yeast MOM38 (Fig. 3A) that efficiently recognized the native protein (anti-MOM38). MOM19 from $N$. crassa was imported into yeast mitochondria and assembled into the yeast receptor complex, as shown by the coprecipitation of MOM19 with anti-MOM38 (Fig. $3 \mathrm{~A}$, lanes 2 and 8 ). Assembly with MOM38 did not occur when reticulocyte lysate containing the radioactively labeled precursor was incubated with lysed mitochondria (Fig. 3A, lane 11), indicating that import of the MOM19 precursor into intact mitochondria is a prerequisite for the assembly of MOM19 with MOM38. MOM72 from N. crassa also correctly assembled into the receptor complex of yeast mitochondria (Fig. $3 \mathrm{~A}$, lanes 5 and 8 ), showing a high conservation of the mitochondrial protein import machinery between $N$. crassa and $S$. cerevisiae.

Yeast mitochondria were pretreated with trypsin so that surface receptors, but not MOM38, were degraded, leading to inhibition of import of various precursor proteins (Fig. 3B) $(4,17)$. Import and assembly of MOM19, however, were still possible. To further analyze whether MOM38 is needed 
for the import of MOM19, we sought to determine whether antibodies to yeast MOM38 (anti-MOM38) affected the import and assembly of MOM19. Prebinding of anti-MOM38 to mitochondria inhibited the import of MOM19 (Fig. 3C), confirming that MOM38 is involved in this process.

The studies conducted thus far indicate that components of the mitochondrial protein import machinery participate in their own biogenesis pathway. These components include mitochondrial hsp70 (18), the mitochondrial processing peptidase $(10,19)$, and hsp60 (20). MOM19 is a component of the import machinery that does not need its own function or that of an analogous component (receptor) for import, although the involvement of an additional unknown component cannot be fully excluded. We suggest that the receptor-independent interaction with MOM38 represents an evolutionary remnant form of mitochondrial protein import, allowing specific import without a need for surface receptors. This finding sheds new light on a previous unexpected result, namely, the import of a number of authentic mitochondrial precursor proteins into mitochondria that lack surface receptors (21). This so-called bypass import occurred with a low efficiency in most but not all cases; its mechanism and specificity remained unclear. The import of MOM19 shows that the interaction with MOM38 allows a specific and highly efficient import in the absence of surface receptors, raising a similar possibility for other precursor proteins [this pathway has to be distinguished from the unique import pathway of the precursor of cytochrome $c$ that possesses an endogenous membrane insertion activity and does not use any of the known MOM proteins; the import of this precursor is controlled by the specific interaction with the cytochrome $c$ heme lyase in the intermembrane space $(2,3,11)]$. The ability of MOM38 to target and insert mitochondrial precursor proteins could be harmful to the cell; mistargeting of MOM38 to another cellular compartment might lead to import of MOM19, which would allow the efficient targeting of many mitochondrial proteins to another compartment. This possibility can be excluded, because the biogenesis of MOM38 strictly depends on the presence of a mitochondrial surface receptor (22). Therefore, the early components of the mitochondrial protein import machinery cannot effect their own import, so an effective control system exists for the specific assembly of the protein import apparatus only at the appropriate location.

\section{REFERENCES AND NOTES}

1. M. G. Douglas, M. McCammon, A. Vassarotti, Microbiol. Rev. 50, 166 (1986); A. Horwich, Curr. Opin. Cell Biol. 2, 625 (1990).

2. K. P. Baker and G. Schatz, Nature 349, 205 (1991); N. Pfanner, T. Söllner, W. Neupert, Trends Biochem. Sci. 16, 63 (1991).

3. T. Söllner, G. Griffiths, R. Pfaller, N. Pfanner, W. Neupert, Cell 59, 1061 (1989).

4. H. F. Steger et al., J. Cell Biol. 111, 2353 (1990).

5. T. Söllner et al., in preparation.

6. T. Söllner, R. Pfaller, G. Griffiths, N. Pfanner, W. Neupert, Cell 62, 107 (1990).

7. N. Pfanner and W. Neupert, J. Biol. Chem. 262, 7528 (1987)
8. R. Pfaller, H. F. Steger, I. Rassow, N. Pfanner, W. Neupert, J. Cell Biol. 107, 2483 (1988)

9. M. Kiebler et al., Nature 348, 610 (1990).

10. H. Schneider, M. Arrez, E. Wachter, W. Neupert, J. Biol. Chem. 265, 9881 (1990).

11. R. A. Stuart, W. Neupert, M. Tropschug, EMBOJ 6, 2131 (1987)

12. P. W. Chou and G. D. Fasman, Annu. Rev. Biochem. 47, 251 (1978).

13. A. Noegel, W. Witke, M. Schleicher, FEBS Lett. 221, 391 (1987)

14. M. Ghislain, A. Schlesser, A. Goffeau, J. Biol. Chem. 262, 17549 (1987).

15. D. Vestweber, I. Brunner, A. Baker, G. Schat, Nature 341, 205 (1989).

16. K. P. Baker, A. Schaniel, D. Vestweber, G. Schatz, ibid. 348, 605 (1990).

17. H. Riezman, R. Hay, C. Witte, N. Nelson, G. Schatz, EMBO J. 2, 1113 (1983).

18. P. J. Kang et al., Nature 348, 137 (1990).

19. C. Witte, R. E. Jensen, M. P. Yaffe, G. Schat, EMBO J. 7, 1439 (1988); M. Yang et al., J. Biol. Chem. 266, 6416 (1991).

20. M. Y. Cheng, F.-U. Hartl, A. L. Horwich, Nature 348,455 (1990).

21. R. Pfaller, N. Pfanner, W. Neupert, J. Biol. Chem. $\infty$ 264, 34 (1989); N. Pfanner, R. Pfaller, W. Neu-O pert, Trends Biochem. Sci. 13, 165 (1988); B. R. Miller and M. G. Cumsky, J. Cell Biol. 112, 833 (1991)

22. T. Söllher, W. Neupert, N. Pfanner, in preparation.'

23. R. A. Young and R. W. Davis, Science 222, 778 (1983).

24. C. Eckerskorn, H. Mewes, H. Goretzki, F. Lottspeich, Eur. J. Biochem. 176, 509 (1988).

25. C. Eckerskorn and F. Lottspeich, Chromatographio 28, 92 (1989).

26. T. Söllner, J. Rassow, N. Pfanner, Methods Cell Biol. ठิ 34, 345 (1991).

27. We thank $H$. Bujard for the vector pUHE, G. Arnold and I. Leitner for the synthesis of oligonucleotides, R. Zimmermann and M. Sagstetter for $\mathbb{C}$ isolated microsomes, H. Feldmann for help with computer analysis, and U. Hanemann for expert $O$ technical assistance. Supported by the Deutsche Forschungsgemeinschaft (Sonderforschungsbere- $\frac{O}{1}$ ich 184, project Bl) and the Genzentrumes München.

11 July 1991; accepted 20 September 1991 